\title{
Synthesis and Characterization of New Biodegradable Chitosan/Polyvinyl Alcohol/Cellulose Nanocomposite
}

\author{
Alireza Samzadeh-Kermani*, Negin Esfandiary \\ Department of Chemistry, Faculty of Science, University of Zabol, Zabol, Iran \\ Email: *drsamzadeh@gmail.com,neginchemist@yahoo.com \\ Received 27 October 2015; accepted 3 February 2016; published 6 February 2016 \\ Copyright $@ 2016$ by authors and Scientific Research Publishing Inc. \\ This work is licensed under the Creative Commons Attribution International License (CC BY). \\ http://creativecommons.org/licenses/by/4.0/ \\ (c) () Open Access
}

\begin{abstract}
In this report, a new nanocomposite based on chitosan/polyvinyl alcohol/nanocrystalline cellulose (Cts/PVA/NCC) was synthesized. The morphology and particle size of NCC and nanocomposites were studied by scanning electron microscopy (SEM), X-ray diffraction (XRD) analysis and Fourier transform infrared (FT-IR) spectroscopy. According to XRD results, the size of NCC was found to be at the range of 15 - $17 \mathrm{~nm}$. SEM images showed the rod-like shape of NCC whiskers. Finally, biodegradation and swelling studies were performed on Cts/PVA/NCC nanocomposites.
\end{abstract}

\section{Keywords}

Nanocomposite, Nanocrystalline Cellulose, Chitosan, Polyvinyl Alcohol, Biodegradation

\section{Introduction}

Nanostructures are produced from nanofillers which are dispersed in a polymer matrix. Incorporation of small amounts of nanometer-sized fillers can yield composites with enhanced properties earnestly required for many industrial and technological applications [1]. Naturally biopolymers, like polysaccharides can be made into either coatings or stand-alone films [2]. Many studies on biopolymer films for food packaging applications have been reported [3]. The production of NCC has gained increasing attention in recent years. Cellulose, one of the world's most abundant, natural and renewable biopolymer resources, is widely present in various forms of biomass, such as plants. In cellulosic plant fibers, cellulose is present in an amorphous form, but is associated with

${ }^{*}$ Corresponding author.

How to cite this paper: Samzadeh-Kermani, A. and Esfandiary, N. (2016) Synthesis and Characterization of New Biodegradable Chitosan/Polyvinyl Alcohol/Cellulose Nanocomposite. Advances in Nanoparticles, 5, 18-26. 
crystalline phases through both intermolecular and intramolecular hydrogen bondings in which cellulose does not melt before thermal degradation [4]. Cellulose is organized in fibrils, which are aligned parallel to each other, surrounded by a matrix of lignin and hemicellulose. The properties of cellulose including mechanical state, low density and biodegradability [5] depend on the type of cellulose which is present. Cellulose macromolecule consists of $\beta$-1, 4-D-linked glucose chains with molecular formula $\left(\mathrm{C}_{6} \mathrm{H}_{10} \mathrm{O}_{5}\right)_{\mathrm{n}}$ through an acetal oxygen which covalently bonds $\mathrm{C}-1$ of one glucose ring to $\mathrm{C}-4$ of the other [6]. Owing to the abundance of hydroxyl groups existent on the surface of cellulose nanocrystals, reactive NCC can be modified with different chemical groups to accomplish the expected surface modification like esterification and silylation or polymer grafting, which could successfully functionalize NCC and facilitate its dispersion into different polymer matrices [7]. Therefore, NCC is considered as one of the ideal nano-reinforcing agents for polymer matrices (including water soluble and water-insoluble polymer systems) and has been used into many polymer matrices to produce reinforced nanocomposites [8]. In addition, low density, low energy consumption, inherent renewability, biodegradability and biocompatibility are also good advantages of environmentally-friendly NCC [9]. Because of good dispersion of NCC in water [10], fabrication and application of hydrogels including NCC without modification have many advantages versus other nanofillers such as polymer and metal nanoparticles [11]. The improved interface between nanofillers and polymer matrix is beneficial to the properties of polymer-based nanocomposites [12]. In nanocomposites, hydrogen bonding between NCC and polymer matrix plays an important role in determining polymer-NCC interaction. Strong hydrogen bonding between PVA and NCC was confirmed by observing the band gap between 3550 and $3200 \mathrm{~cm}^{-1}$ in Fourier transform infrared spectra (FTIR). In addition to hydrogen bonding, covalent bonding also provides an enhancement in polymer-nanofiller interface to achieve optimal nanobiocomposite properties [13]. NCC was made in spherical state [14] [15], or rod-like highly crystalline nanocrystals [6] [16]-[18], which was obtained by acid hydrolysis of cellulosic fibers and microfibrillated cellulose (MFC) resulting from disintegration of cellulose fibers under high shearing and impact forces [19]. NCC, which is obtained via acid hydrolysis of cellulose, typically has a wide range in size. With increasing consumption consciousness about petroleum-based polymer materials, the development of fully biodegradable, ecofriendly and bio-based nanocomposites has gained more and more attention both in industrial and academic fields [20]. The so-called "green" composites are derived from different natural resources such as plants or animals [21]. PVA is a material with technological potential which has a wide range of applications due to its unique physical and chemical properties [22]. It is a nontoxic, highly crystalline matter and has good filmforming and high hydrophilic properties. PVA, cellulose and Cts are polar polymers; thus a nonocomposite of PVA, Cts and NCC is likely to produce a material including excellent mechanical properties. Embedding NCC into PVA matrix changes the physicochemical properties of PVA and improves polymer structure in both molecular and morphological levels [23]. We have chosen Cts because it is one of the strongest biopolymers containing reactive amino groups. Moreover, this biopolymer has several important properties such as biocompatibility and anti-bacterial properties, which made it a suitable material for biomedical applications such as drug delivery, tissue engineering, wound healing and various antimicrobial strategies [24]. Also, Cts films have been used for food packaging, mainly due to their non-toxicity and biodegradability [25]. In this study we have prepared NCC from Whatman No. 1 filter paper via acid hydrolysis.

\section{Experiments}

\subsection{Materials}

The materials used in this study, consist of Whatman No. 1 filter paper as a precourser for NCC, acetic acid (analytical purity), Sulfuric acid (98\%) for acidic hydrolysis, PVA and low-molecular-weight Chitosan as matrices, which were obtained from Merk (Darmstadt, Germany) Company Inc.

\subsection{Preparation of Nanocrystalline Cellulose}

The NCC was obtained via acidic hydrolysis using traditional method. A Whatman No. 1 filter paper (98\% $\alpha$-cellulose, $80 \%$ crystallinity) was chopped and transferred into $70 \mathrm{ml}$ of deionized water and blended by a (10 Speed Osterizer) Blender to turn a pulp. The pulp was filtered by a Buchner Funnel under vaccume filtration. Then $40 \mathrm{ml}$ Sulfuric acid (98\%) was added dropwise to the solution under vigorous stirring at $45^{\circ} \mathrm{C}$ until the slurry turned to a milky mixture for about 2 hours. After dilution with $200 \mathrm{ml}$ of cold deionized water, the mix- 
ture was subjected to five washing/centrifugation cycles using a centrifuge apparatus (14,000 g, 15 min, Eppendorf, Germany). When $\mathrm{pH}$ was reached to about 4 - 5, the fine cellulose particles were dispersed into aqueous supernatant. The residue containing NCC, was then filtered.

\subsection{Preparation of Cts/PVA/NCC Nanocomposite}

Cts/PVA/NCC was prepared using traditional method. $1 \mathrm{~g}$ Cts was dissolved in $100 \mathrm{ml}$ acetic acid $(0.1 \mathrm{M})$ and stirred for 6 hours at room temperature. Then the solution was filtered in order to remove undissolved materials. PVA was dissolved in $20 \mathrm{ml}$ of hot distilled water under constant stirring and then added to Cts solution followed by stirring for 2 hours. Various weight ratios of NCC (0, 5, 10 and 15\% w/w) were added directly into Cts/PVA solution and then stirred for 24 hours. The mixtures were casted into petri dishes and placed in an airconvection oven at $60^{\circ} \mathrm{C}$ for 12 hours. The average thickness of every prepared film was about $1 \mathrm{~mm}$.

\section{Characterization Methods}

\subsection{Fourier-Transform Infrared (FTIR) Spectroscopy}

FT-IR spectroscopy was used to confirm that a reaction was occurred between PVA, Cts and NCC. The IR spectra of PVA/Cts/NCC films were recorded using a Bruker Optics Ft Tensor 27, Germany Instrument. FTIR spectra of cellulosic samples were recorded in the range of $400-4000 \mathrm{~cm}^{-1}$ by the resolution of $4 \mathrm{~cm}^{-1}$. The samples were grounded into powder, mixed with $\mathrm{KBr}$ and then converted into thin pellets.

\subsection{X-Ray Diffraction (XRD) Analysis}

An X-ray diffractometer (X Pert Prompd, Phillips, Netherlands) was used to investigate the crystallinity of nanocellulose. Milled sample powder was analyzed using a $\mathrm{Cu}-\mathrm{K}_{\alpha}(\lambda=1.54$ angstrom) analyser. The angle of incidence was varied from $4^{\circ}$ to $80^{\circ}$ by the step of $0.02^{\circ}$ and at the rate of $3^{\circ} / \mathrm{min}$ at $40 \mathrm{kV}$ and $30 \mathrm{~mA}$. The Segal method was used to calculate the sample crystallinity, using the height of the 200 peak $\left(\mathrm{I}_{200}, 2 \theta=22.93^{\circ}\right)$ and the lowest height between the 200 and 110 peaks $\left(\mathrm{I}_{\mathrm{AM}}, 2 \theta=18^{\circ}\right)$. $\mathrm{I}_{200}$ represents both crystalline and amorphous regions while $\mathrm{I}_{\mathrm{AM}}$ represents amorphous material only.

\subsection{Scanning Electron Microscopy (SEM) Analysis}

Scanning electron microscopy (SEM) photographs of the samples were captured using (Hitachi S4160, Germany) electron microscope. The samples were coated with gold using sputtering technique. Scanning electron microscopy (SEM) was used to investigate the morphology of different types of films.

\subsection{Gel Swelling Property}

First the films were dried at $40^{\circ} \mathrm{C}$ for 12 hours in an incubator and then weighed. Dried films were then immersed in distilled water for 1, 2, 4 and 8 hours. Wet weight of the films was measured after removing them from water and obliterating the surface adsorbed water. Then films were weighed immediately [26]. Gel swelling property of films was calculated by the following equation:

$$
S=\left[\frac{w_{s}-w_{d}}{w_{d}}\right] \times 100
$$

in which, $S$ is the percentage of water adsorption of films at equilibrium state, $w_{s}$ and $w_{d}$ are the weights (in grams) of samples in swollen and dried states, respectively.

\subsection{Biodegradation Property}

Biodegradation property of different PVA/Cts/NCC films was determined by exposing the samples to compost mud. In this study, the degradation of films was evaluated by measurement of their weight loss, which refers to erosion of the molecules from solid phase to aqueous phase. The dissolved components were easily degraded by micro organisms in a natural environment. 


\section{Results and Discussion}

\subsection{FTIR Spectroscopy Analysis}

FT-IR spectra of NCC and the nanocomposites were shown in Figure 1. The spectrum of NCC was exhibited a broad band in the region of $3500-3200 \mathrm{~cm}^{-1}$, which indicated the inter hydrogen bonded O-H stretching vibration of the $\mathrm{OH}$ groups in cellulose molecule. The spectra of all other samples were shown characteristic C-H stretching vibration around $2900 \mathrm{~cm}^{-1}$ for C-H stretching and the peak in the region of about $1641 \mathrm{~cm}^{-1}$ which was attributed to glycosidic C-O bonds. Besides, the vibrational peak at $1365 \mathrm{~cm}^{-1}$ in the samples B, C, D and E was related to the bending vibration of $\mathrm{C}-\mathrm{H}$ bonds in aromatic ring. The band around $1423 \mathrm{~cm}^{-1}$ was attributed to the aliphatic C-H stretching of PVA. Furthermore, the peaks around $1430 \mathrm{~cm}^{-1}$ were associated with the C-H in plane bending of NCC.

\subsection{X-Ray Diffraction Studies}

The crystallinity of NCC was calculated to be $81.5 \%$ from Segal Method. This value was in the range of published values $86.7 \%$ for commercial microfibrillated cellulose (MFC). Pure Cts was shown two peaks at $2 \theta$ of $9.37^{\circ}, 19.56^{\circ}$ and a broad peak appearing at $2 \theta$ values in the range $19^{\circ}-28^{\circ}$ was generally pertinent to the polymeric PANi chains. The peaks at $2 \theta$ values of $7.12^{\circ}$ for MMT and $6.09^{\circ}$ for MMT/Cts were also observed. As shown in Figure 2, all the four diffractograms display two well-defined peaks around $2 \theta$ of $12.5^{\circ}$ (for 110 plane) and $2 \theta$ of $22.5^{\circ}$ (for 200 plane) characteristic of cellulose [4]. Proper control of the hydrolysis conditions were resulted in selective degradation and preferential removal of amorphous cellulosic fraction. However, the average crystallite size was obtained from X-ray diffraction data using Scherrer's formula:

$$
D=\frac{K \lambda}{\beta \operatorname{Cos} \theta}
$$

where $k=0.94, \lambda=0.154056 \mathrm{~nm}$ and $\beta$ is the full width at half maximum (FWHM) in radians. The prepared NCC had rectangular shape with average dimensions of $15.7 \mathrm{~nm}$. The above experimental observations were indicated that NCC belonged to semi-crystalline polymer, which were contained crystalline and amorphous regions. Accordingly, the above results were demonstrated that the hydrolysis was taken place in the amorphous region. This increase of crystallinity after acidic treatment has been reported by several authors [27] [28].

\subsection{Scanning Electron Microscopy (SEM) Analysis}

The morphology of Cts/PVA/NCC nanocomposites was assigned using SEM. Scanning electron micrographs of the nanocomposite films with different contents of NCC were shown in Figure 3. The random orientation and good dispersion of NCC in matrices was observed. These results were indicated an excellent compatibility between the three components of every nanocomposite. According to the SEM results, it was obvious that the whiskers of NCC in nanocomposites were rod like. The morphology of NCC was appeared unchanged after blending with Cts/PVA matrix.

\subsection{Gel Swelling Property Analysis}

Figure 4 was illustrated the effect of the concentration of NCC on swelling percentage and water uptake of Cts/ PVA films. The presence of NCC in the films was reduced the swelling percentage of Cts/PVA films. Water uptake of nanocomposites was depended on the nature of matrix and filler. The decreased water uptake could be ascribed to the high crystallization of NCC which was less hydrophilic than Cts/PVA composite and the formation of strong filler-matrix interactions [26] [29] [30]. NCC was acted as an interpenetrating network within the matrix and prevented the swelling of the Cts/PVA films when taken into the water [31].

\subsection{Biodegradation Analysis}

The weight loss in biodegradation of Cts/PVA and Cts/PVA/NCC films was shown in Table 1. Accordingly, it was observed that the degradation occurred in a faster rate in the presence of NCC in the Cts/PVA matrix. Consequently, the nanocomposites could be easily degraded in natural condition. 

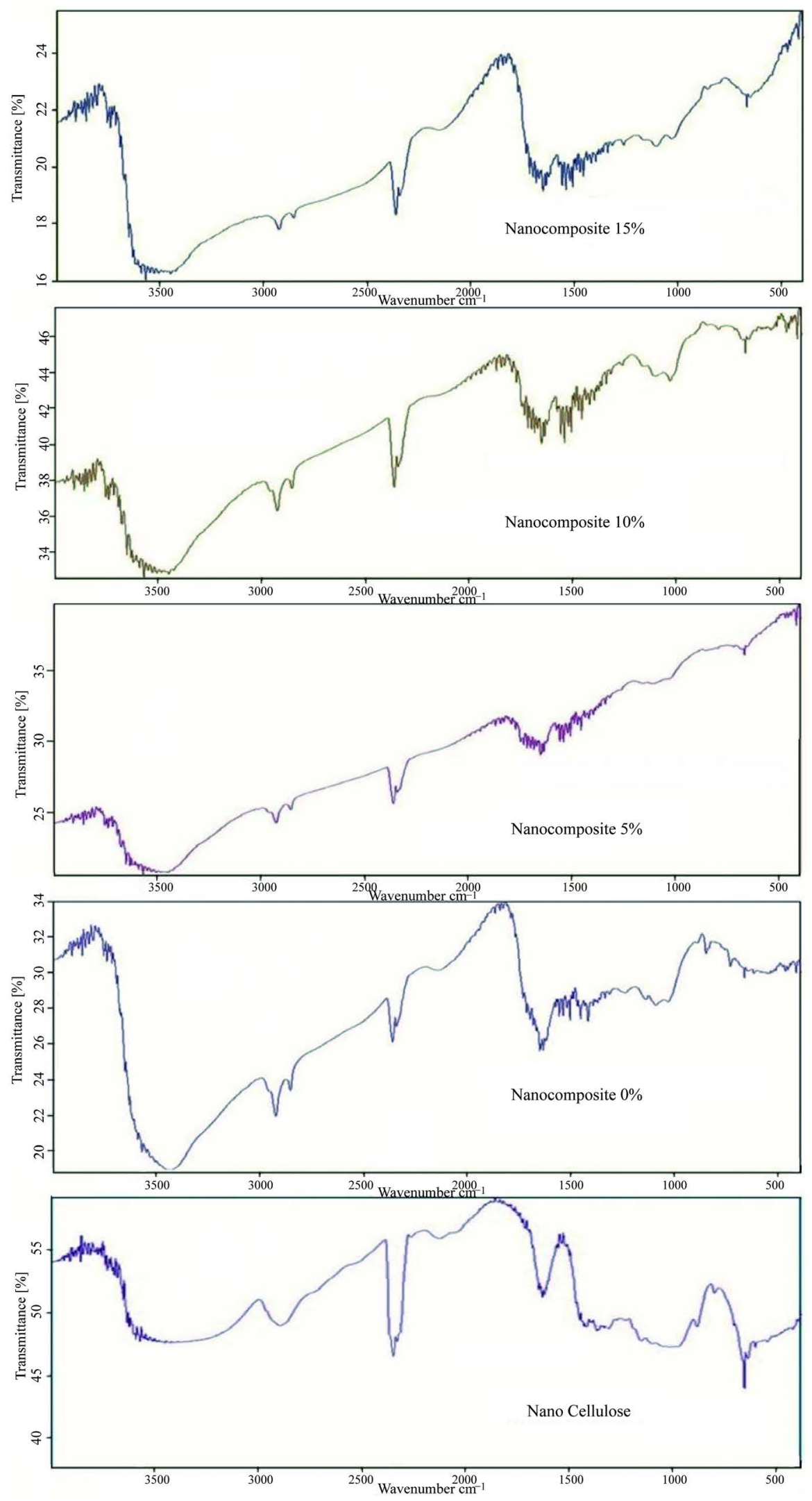

Figure 1. FT-IR spectra of NCC and nanocomposites with different NCC concentrations. 

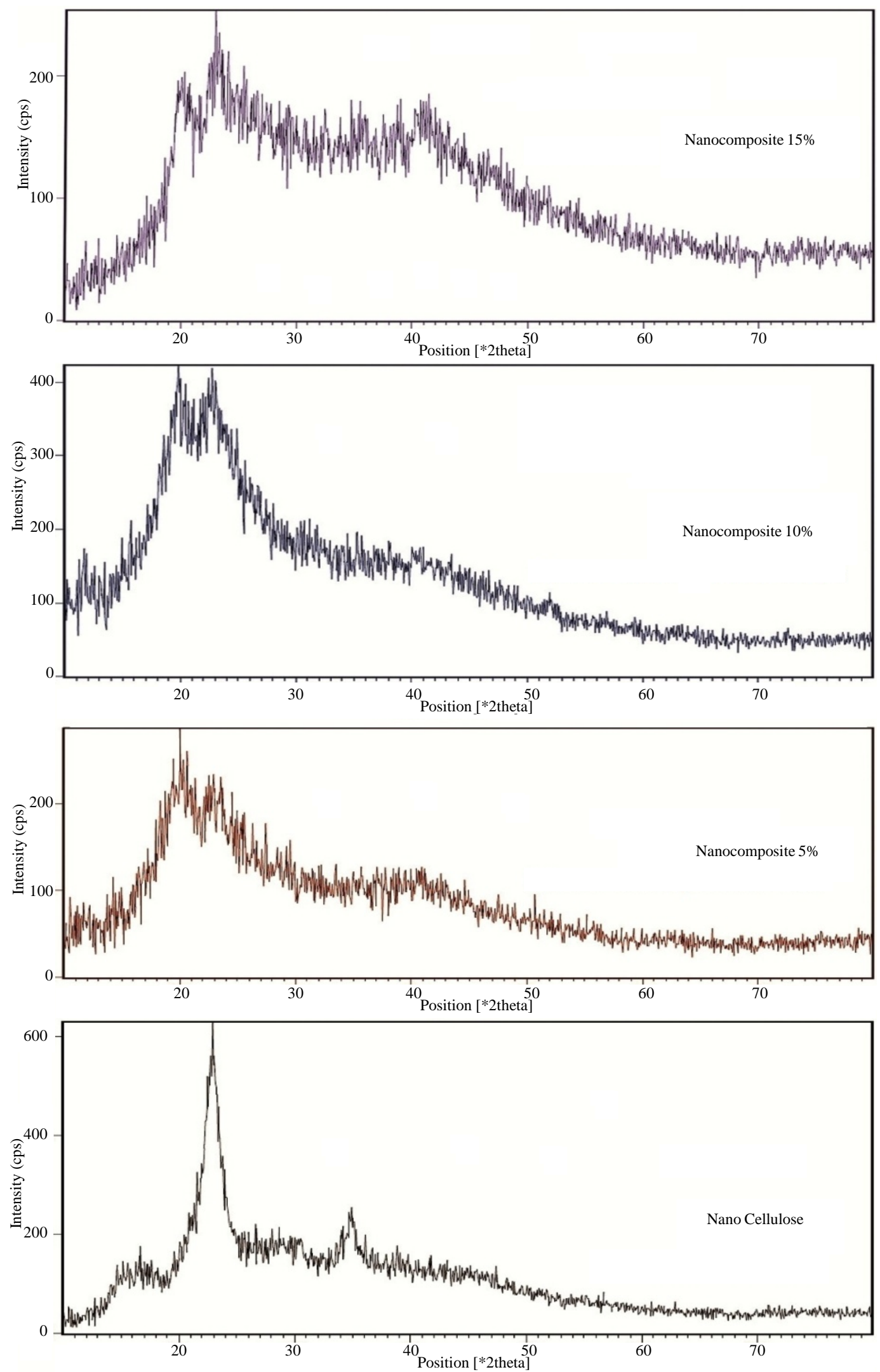

Figure 2. XRD patterns of NCC and nanocomposites with different NCC. 

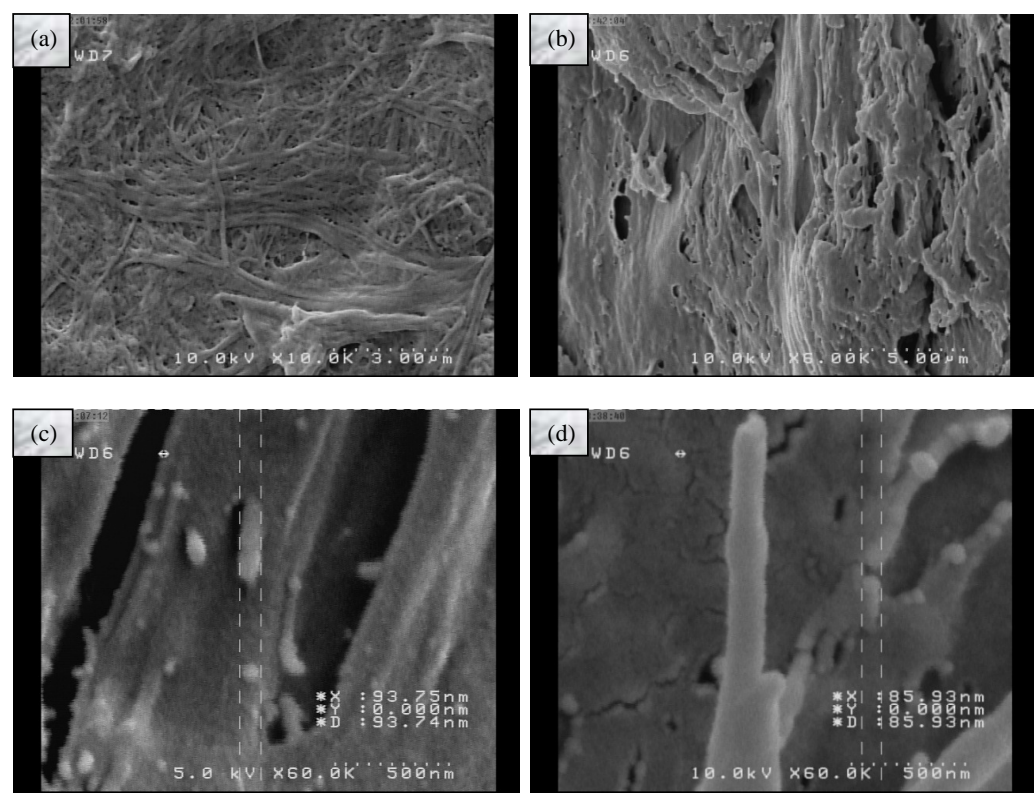

Figure 3. FESEM pictures of (a) NCC, (b) nanocomposite 5\%, (c) nanocomposite10\% and (d) nanocomposite $15 \%$.

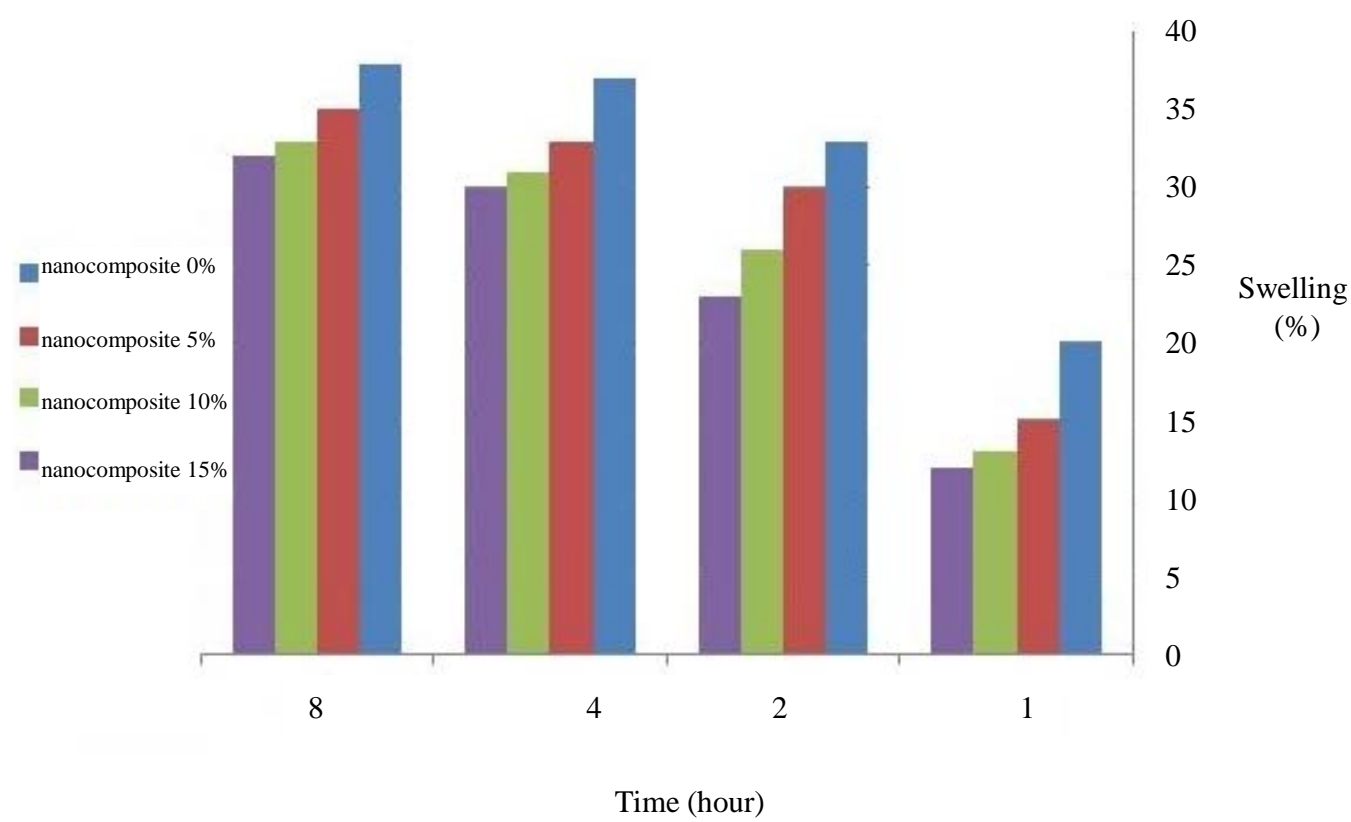

Figure 4. The effect of NCC content in the gel swelling property of Cts/PVA films.

Table 1. Biodegradation for the Cts/PVA and Cts/PVA/NCC films.

\begin{tabular}{ccccc}
\hline \multirow{2}{*}{ Films } & \multicolumn{3}{c}{ Weight loss $(\mathbf{g})$} \\
\cline { 2 - 5 } & 1st day & 2nd day & 4th day & 5th day \\
\hline Nanocomposite 0\% & 0.16 & 0.12 & 0.11 & 0.09 \\
Nanocomposite 5\% & 0.21 & 0.23 & 0.13 & 0.07 \\
Nanocomposite 10\% & 0.32 & 0.30 & 0.15 & 0.03 \\
Nanocomposite 15\% & 0.40 & 0.33 & 0.19 & 0.02 \\
\hline
\end{tabular}




\section{Conclusion}

In this research, NCC was synthesized from Whatmann No. 1 filter paper. Cts/PVA/NCC nanocomposites were prepared in different concentrations of NCC [5\% (B), 10\% (C) and 15\% (D)]. Further studies should be focused on the investigation of other potential applications of NCC and its nanocomposites in combination with other polymers. NCCs which were isolated by sulfuric acid hydrolysis, were rod-like whiskers with an average size of about $15.7 \mathrm{~nm}$ observed by XRD analysis, and the crystallinity of NCC was about 81.5\%. SEM images of NCC showed the dimensions of about $85 \mathrm{~nm}$ wide. NCC improved the barrier properties of Cts/PVA composite films via reduction of swelling property. Although, a comparison with related literature results showed that the nanocomposites which were investigated in this work were amongst the best materials reported so far, this approach appeared really promising for the design of a wide range of new related nanocomposites. Surface morphology of nanocomposite films revealed a homogeneous dispersion of NCC into the Cts/PVA matrix. The prepared Cts/ PVA/NCC films were biodegradable.

\section{Acknowledgements}

This research has been accomplished under financial support of the Department of Chemistry, Faculty of Science, and cordially laboratorial collaboration of our colleagues at the Department of Agronomy, Faculty of Agriculture, University of Zabol, which should be appreciated.

\section{References}

[1] Whitesides, G.M. (2005) Nanoscience, Nanotechnology, and Chemistry. Nanoscience and Chemistry, 1, 172-179. http://dx.doi.org/10.1002/smll.200400130

[2] Kester, J.J. and Fennema, O.R. (1986) Edible Films and Coatings: A Review. Food Technology, 40, 47-59.

[3] Gennadios, A. (2002) Protein-Based Films and Coatings. CRC Press, Boca Raton, 367-392. http://dx.doi.org/10.1201/9781420031980

[4] Klemm, D., Heublein, B., Fink, H.P. and Bohn, A. (2005) Cellulose: Fascinating Biopolymer and Sustainable Raw Material. Angewandte Chemie International Edition, 44, 3358-3393. http://dx.doi.org/10.1002/anie.200460587

[5] Zimmerman, T., Pohler, E. and Schwaller, P. (2005) Mechanical and Morphological Properties of Cellulose Fibril Reinforced Nanocomposites. Advanced Engineering Materials, 12, 1156-1161. http://dx.doi.org/10.1002/adem.200500157

[6] Azizi-Samir, M.A.S., Alloin, F. and Dufresne, A. (2005) Review of Recent Research into Cellulosic Whiskers, Their Properties and Their Application in Nanocomposite Field. Biomacromolecules, 6, 612-626. http://dx.doi.org/10.1021/bm0493685

[7] Habibi, Y., Lucia, L.A. and Rojas, O.J. (2010) Cellulose Nanocrystals: Chemistry, Self-Assembly, and Applications. Chemical Reviews, 110, 3479-3500. http://dx.doi.org/10.1021/cr900339w

[8] Cao, X.D., Habibi, Y., Magalhaes, W.L.E., Rojas, O.J. and Lucia, L.A. (2011) Cellulose Nanocrystals-Based Nanocomposites: Fruits of a Novel Biomass Research and Teaching Platform. Current Science, 100, 1172-1176.

[9] Siro, I. and Plackett, D. (2010) Microfibrillated Cellulose and New Nanocomposite Materials: A Review. Cellulose, 17, 459-494. http://dx.doi.org/10.1007/s10570-010-9405-y

[10] Liang, S.M., Zhang, L.N., Li, Y.F. and Xu, J. (2007) Fabrication and Properties of Cellulose Hydrated Membrane with Unique Structure. Macromolecular Chemistry and Physics, 208, 594-602. http://dx.doi.org/10.1002/macp.200600579

[11] Wu, Y.T., Zhou, Z., Fan, Q.Q., Chen, L. and Zhu, M.F. (2009) Facile In-Situ Fabrication of Novel Organic Nanoparticle Hydrogels with Excellent Mechanical Properties. Journal of Materials Chemistry, 19, 7340-7346. http://dx.doi.org/10.1039/b909125d

[12] Zhang, Y., Yu, J.R., Zhou, C.J., Chen, L. and Hu, Z.M. (2010) Preparation, Morphology, and Adhesive and Mechanical Properties of Ultrahigh-Molecular-Weight Polyethylene/SiO ${ }_{2}$ Nanocomposite Fibers. Polymer Composites, 31, 684690.

[13] Zhou, C.J., Wang, S.F., Zhang, Y., Zhuang, Q.X. and Han, Z.W. (2008) In Situ Preparation and Continuous Fiber Spinning of Poly(p-phenylenebenzobisoxazole) Composites with Oligo-Hydroxyamide-Functionalized Multi-Walled Carbon Nanotubes. Polymer, 49, 2520-2530. http://dx.doi.org/10.1016/j.polymer.2008.04.003

[14] Pu, Y.Q., Zhang, J.G., Elder, T., Deng, Y., Gatenholm, P. and Ragauskas, A. (2007) Investigation into Nanocellulosics versus Acacia Reinforced Acrylic Films. Composites Part B: Engineering, 38, 360-366. http://dx.doi.org/10.1016/j.compositesb.2006.07.008 
[15] Zhang, J., Jiang, N., Dang, Z., Elder, T.J. and Ragauska, A.J. (2008) Oxidation and Sulfonation of Cellulosics. Cellulose, 15, 489-496. http://dx.doi.org/10.1007/s10570-007-9193-1

[16] Lima, M.M.D. and Borsali, R. (2004) Rod-Like Cellulose Microcrystals: Structure, Properties and Applications. Macromolecular Rapid Communications, 25, 771-787. http://dx.doi.org/10.1002/marc.200300268

[17] Dufresne, A. (2006) Comparing the Mechanical Properties of High Performances Polymer Nanocomposites from Biological Sources. Journal of Nanoscience and Nanotechnology, 6, 322-330.

[18] Dufresne, A. (2008) Polysaccharide Nanocrystal Reinforced Nanocomposites. Canadian Journal of Chemistry, 86, 484-494. http://dx.doi.org/10.1139/v07-152

[19] Teixeira, E.M., Pasquini, D., Curvelo, A.A.S., Corradini, E., Belgacem, M.N. and Dufresne, A. (2009) Cassava Bagasse Cellulose Nanofibrils Reinforced Thermoplastic Cassava Starch. Carbohydrate Polymers, 78, 422-431. http://dx.doi.org/10.1016/j.carbpol.2009.04.034

[20] Kim, J.T. and Netravali, A.N. (2010) Mechanical, Thermal, and Interfacial Properties of Green Composites with Ramie Fiber and Soy Resins. Journal of Agricultural and Food Chemistry, 58, 5400-5407. http://dx.doi.org/10.1021/jf100317y

[21] Khalil, H.P.S.A., Bhat, A.H. and Yusra, A.F.I. (2012) Green Composites from Sustainable Cellulose Nanofibrils: A Review. Carbohydrate Polymers, 87, 963-979. http://dx.doi.org/10.1016/j.carbpol.2011.08.078

[22] Masuhiro, T., Giuliano, F. and John, S.C. (1994) Structure and Compatibility of Poly(vinyl alcohol)-Silk Fibroin (PVA/SA) Blend Films. Journal of Polymer Science B: Polymer Physics, 32, 243-248. http://dx.doi.org/10.1002/polb.1994.090320205

[23] Siddaramaiah, R.T., Ravi, P., Kumar, K.P. and Jagadeesh, K.S. (1999) Effect of Fillers on the Properties of LDPE Films. Journal of Polymer Materials, 16, 233-237.

[24] Dash, M., Chiellini, F., Ottenbrite, R.M. and Chiellini, E. (2011) Chitosan-A Versatile Semi-Synthetic Polymer in Biomedical Applications. Progress in Polymer Science, 36, 981-1014. http://dx.doi.org/10.1016/j.progpolymsci.2011.02.001

[25] De Azeredo, H.M.C. (2009) Nanocomposites for Food Packaging Applications. Food Research International, 42, 1240-1253. http://dx.doi.org/10.1016/j.foodres.2009.03.019

[26] Jin, J., Song, M. and Hourston, D.J. (2004) Novel Chitosan-Based Films Cross-Linked by Genipin with Improved Physical Properties. Biomacromolecules, 5, 162-168. http://dx.doi.org/10.1021/bm034286m

[27] Azizi-Samir, M.A.S., Alloin, F., Paillet, M. and Dufresne, A. (2004) Tangling Effect in Fibrillated Cellulose Reinforced Nanocomposites. Macromolecules, 37, 4313-4316. http://dx.doi.org/10.1021/ma035939u

[28] Tang, L.G., Hon, D.N.S., Pan, S.H., Zhu, Y.Q., Wang, Z. and Wang, Z.Z. (1996) Evaluation of Microcrystalline Cellulose. I. Changes in Ultrastructural Characteristics during Preliminary Acid Hydrolysis. Journal of Applied Polymer Science, 59, 483-488. http://dx.doi.org/10.1002/(SICI)1097-4628(19960118)59:3<483::AID-APP13>3.0.CO;2-V

[29] Dufresne, A., Dupeyre, D. and Vignon, M.R. (2000) Cellulose Microfibrils from Potato Tuber Cells: Processing and Characterization of Starch-Cellulose Microfibril Composites. Journal of Applied Polymer Science, 76, 2080-2092. http://dx.doi.org/10.1002/(SICI)1097-4628(20000628)76:14<2080::AID-APP12>3.0.CO;2-U

[30] Li, Q., Zhou, J. and Zhang, L. (2009) Structure and Properties of the Nanocomposite Films of Chitosan Reinforced with Cellulose Whiskers. Journal of Polymer Science Part B: Polymer Physics, 47, 1069-1077. http://dx.doi.org/10.1002/polb.21711

[31] Svagan, A.J., Hedenqvist, M.S. and Berglund, L. (2009) Reduced Water Vapour Sorption in Cellulose Nanocomposites with Starch Matrix. Composites Science and Technology, 69, 500-506. http://dx.doi.org/10.1016/j.compscitech.2008.11.016 